\title{
Distribución altitudinal de las aves en una zona prioritaria en Sinaloa y Durango, México
}

\author{
Altitudinal distribution of birds in a priority area in Sinaloa-Durango, Mexico
}

\author{
Ma Nelle Medina-Macías ${ }^{1,2}$, Marco Antonio González-Bernal² y Adolfo G. Navarro-Sigüenza ${ }^{1 *}$ \\ ${ }^{1}$ Museo de Zoología, Facultad de Ciencias, Universidad Nacional Autónoma deMéxico, Apartado postal 70-399, 04510 México, D.F., México. \\ ${ }^{2}$ Escuela de Biología, Universidad Autónoma de Sinaloa. Ciudad Universitaria, Culiacán, Sinaloa 80010, México. \\ "Correspondencia:fcvg01@servidor.unam.mx
}

\begin{abstract}
Resumen. En este estudio se documentan los patrones de riqueza de especies y endemismo con respecto a un gradiente altitudinal (300-2 800 m snm) en la región del Espinazo del Diablo (estados de Durango y Sinaloa). Se registró un total de 209 especies de aves, que aunadas a los registros previos en literatura y colecciones conforman una lista regional de 229 especies. Los 3 métodos empleados para reconocer la existencia de asociaciones faunísticas a lo largo del gradiente - el fenograma de similitud, las curvas de atenuación y el análisis de TWINSPAN-, coincidieron en la existencia de 3 pisos altitudinales, por lo que se observa claramente que existe una división de la avifauna en el transecto. La zona reviste una gran importancia para la conservación de los recursos biológicos de México, pues además de contener el reducto de bosque montano húmedo más norteño del oeste de Mesoamérica, la avifauna también resulta importante tanto por su riqueza específica como por el endemismo y presencia de especies de especial interés.
\end{abstract}

Palabras clave: Sinaloa, Durango, avifauna, distribución altitudinal, endemismo.

\begin{abstract}
We document patterns of species richness and endemism in an elevational gradient (300 to $2800 \mathrm{~m}$ ) located in the Espinazo del Diablo region (states of Durango and Sinaloa), as well as its significance for the conservation of the avifauna, that is a global priority due to the presence of endemic and highly endangered taxa. We recorded a total of 209 species of birds in the fieldwork, and adding the records from literature and collections, the list increases to 229 bird species in the area. The 3 methods used for recognizing faunistic assemblages along the elevational gradient -phenetic similarity analysis, faunal congruence curves, and TWINSPAN- recognized 3 altitudinal associations, 1 in the lowlands and 2 in the higher elevations, what represents a clear division of the avifauna. The area is a conservation priority in Mexico, because is the northernmost relict of cloud forest in Mesoamerica, and holds an extraordinary combination of species richness, endemism, and presence of endangered taxa.
\end{abstract}

Key words: Sinaloa, Durango, avifauna, altitudinal distribution, endemism.

\section{Introducción}

El gran interés por los ecosistemas de montaña se debe a que tienen una alta diversidad biológica a lo largo de gradientes altitudinales (Terborgh, 1971; Navarro, 1992; Peterson et al., 1993; Lomolino, 2001; Körner y Spehn, 2002). Las dimensiones verticales de las montañas producen gradientes climáticos con variaciones abruptas o graduales en temperatura, humedad relativa, radiación solar y precipitación, lo cual provoca un efecto en la distribución y abundancia de la flora, y finalmente las comunidades vegetales responsables de la presencia o ausencia de la fauna (Körner, 2000). En diversos estudios (Terborgh, 1971, 1977, 1985; Terborgh y Weske, 1975;

Recibido: 09 enero 2009; aceptado: 07 septiembre 2009
Graham,1990) se discute que las causas que limitan la distribución de las especies son principalmente los factores físicos, la competencia y la presencia de ecotonos, que se han analizado para diversos taxa de vertebrados en diferentes regiones del mundo (Rahbek, 1997; Heaney, 2001; Sánchez-Cordero, 2001; Rickart, 2001).

La región del Espinazo del Diablo, situada en los límites de los estados de Durango y Sinaloa, presenta especies microendémicas como la chara pinta (Cyanocorax dickeyi), el quetzal orejón (Euptilotis neoxenus) y la guacamaya enana (Rhynchopsitta pachyrhyncha), además del aparentemente extinto carpintero imperial (Campephilus imperialis; Lammertink et al., 1997). A pesar de que es una de las regiones más visitadas por ornitólogos y observadores de aves desde hace muchos años, hay pocos estudios publicados sobre esta avifauna 
montana, los cuales se han limitado a guías de campo (Alden, 1969), reportes aislados de colectas o viajes de observaciones (Moore, 1938; Lammertink et al., 1997; Whitney, 1986) y notas sobre la biología de algunas especies (Crossin, 1967; Monterrubio-Rico et al., 2002). En este estudio se documentan los patrones de riqueza de especies y endemismo en un gradiente altitudinal de la zona (300 a $2800 \mathrm{~m}$ snm) en 5 tipos de vegetación. Los datos se correlacionaron con la conservación de la avifauna de la región, que ha demostrado ser una prioridad mundial por la presencia de especies endémicas y amenazadas (Hernández-Baños et al., 1995; Lammertink et al., 1997; Arriaga et al., 2000).

\section{Materiales y métodos}

Área de estudio. El área, conocida como el Espinazo del Diablo, se localiza en la sierra Madre Occidental entre los estados de Sinaloa y Durango (Fig. 1) en medio de los municipios de Concordia (Sinaloa) y Pueblo Nuevo (Durango) en el noroeste de México. Es una zona escarpada que abarca elevaciones desde los $200 \mathrm{~m}$ snm en sus partes bajas, hasta los $3000 \mathrm{~m}$ snm. Incluye 3 tipos de clima de acuerdo con la clasificación de Köppen modificada por

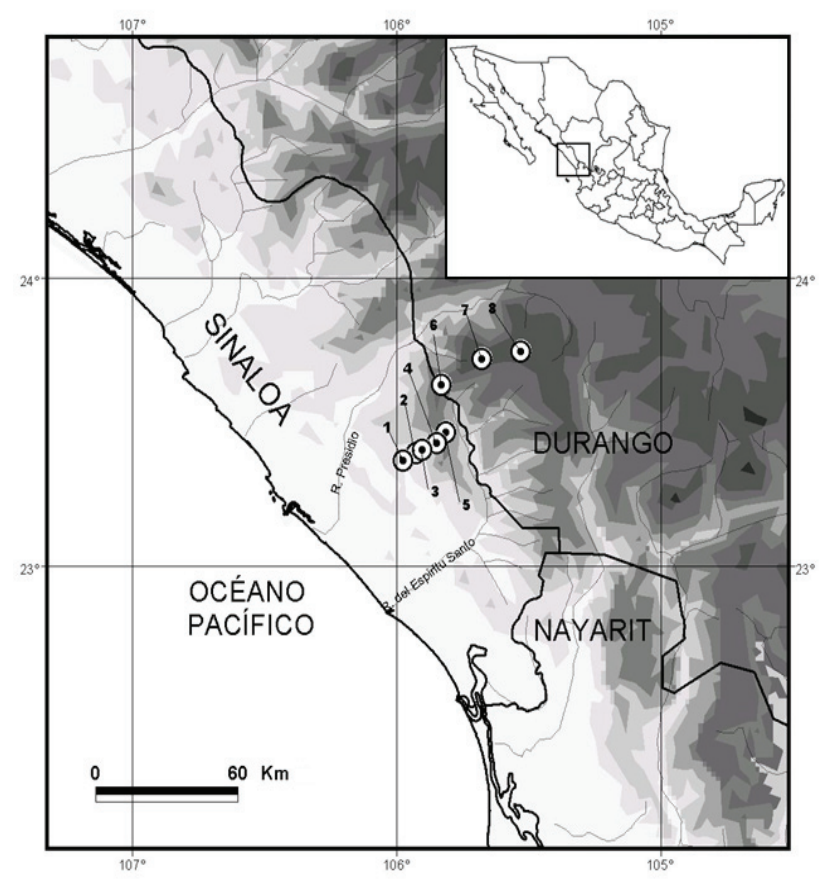

Figura 1. Localización del área de estudio. Los números representan los sitios de muestreo: 1, Magistral; 2, Copala; 3, Rancho Mojocoan; 4, Capilla del Taxte; 5, El Batel; 6, Palmito; 7, Mexiquillo; y 8, Las Rusias. El mapa base es de altitud promedio de CONABIO (http://www.conabio.gob.mx).
García (2004). En la parte baja de la sierra el clima es cálido subhúmedo; semicálido subhúmedo en las zonas intermedias, y templado subhúmedo en las más altas.

En la región existen varios tipos de vegetación (sensu Rzedowski, 1978; Vega et al., 1989). La selva baja caducifolia se localiza en las altitudes menores del transecto en la vertiente del Pacífico; las especies dominantes pertenecen a los géneros Ipomoea, Lysiloma y Bursera y se encuentran elementos de matorral espinoso, como Opuntia y Stenocereus. En algunos sitios hay también árboles altos, como Brosimum alicastrum, Ceiba pentandra y especies del género Ficus. Por arriba de los $900 \mathrm{~m}$ snm se encuentran bosques de Quercus conformados por varias especies: $Q$. castanea, $Q$. enlycheana, $Q$. fulva, $Q$. glaucescens y $Q$. tuberculata (Crossin, 1967). En ambientes muy húmedos de la zona, en cañadas y barrancas entre 1900 y 2200 m snm, existe un bosque mesófilo de montaña (Rzedowzki, 1978); ahí la abundancia de epífitas es notable, se encuentra una gran cantidad de líquenes, helechos y bromelias; en su porción baja, está delimitado por bosque de Quercus y en la alta por bosque de pino; la composición florística la conforman especies como Abies religiosa, Arbutus glandulosa, Clethra lanata, Magnolia shiedeana, Tilia sp., Trema micrantha y Ostrya virginiana, entre otras (Crossin, 1967). El bosque de pino se encuentra como un pequeño manchón a los $1200 \mathrm{~m}$ snm y entre los 2400 y $3000 \mathrm{~m}$ snm. Las especies dominantes son Pinus douglasiana, $P$. herrerae, $P$. leiophylla, $P$. lumholtzii y $P$. oocarpa, mismas que se mezclan con Abies religiosa, Arbutus xalapensis y Styrax argenteus.

Inicialmente, de la base de datos del Atlas de las aves de México se recopilaron los registros de aves para la zona de estudio contenidos en diferentes museos del mundo (Navarro et al., 2003; véase Agradecimientos), así como observaciones y recoleccciones citadas en publicaciones (Rodríguez-Yáñez et al., 1994). Esta información permitió elaborar una lista preliminar de las especies de aves de la región.

Se realizó trabajo de campo en 8 sitios de muestreo en la región localizados en intervalos elevacionales de aproximadamente 300 a $400 \mathrm{~m}$ (Cuadro 1, Fig. 2), intentando que representaran el espectro de condiciones ecológicas relacionadas con la altitud. Se elaboró un perfil de vegetación sobre un mapa a escala 1:250 000 con una longitud de $100 \mathrm{~km}$ (Fig. 2). Se realizaron 7 salidas de campo (Cuadro 1) con duración de 8-5 días cada una, que sumaron em total 67 días de trabajo de campo. En cada salida se visitaron de 2-8 sitios de muestreo dependiendo de la duración de cada uno de los viajes; los muestreos se realizaron de junio de 1998 a abril del 2000. En cada estación se colocaron de 5 a 10 redes ornitológicas de 12 x $2.5 \mathrm{~m}$, expuestas desde el amanecer hasta el atardecer 
Cuadro 1. Características generales y esfuerzo de campo en los sitios de muestreo del área de estudio en los municipios de Concordia (Sinaloa) y Pueblo Nuevo (Durango)

\begin{tabular}{|c|c|c|c|c|}
\hline Localidades & $\begin{array}{l}\text { Trabajo de } \\
\text { campo total } \\
\quad \text { (dias) }\end{array}$ & $\begin{array}{l}\text { Altitud } \\
\text { ( } m \text { snm) }\end{array}$ & Tipo de vegetación & Fechas de muestreo \\
\hline Magistral, Sinaloa & 10 & 300 & Selva baja caducifolia & nov88, oct99, dic99, mar00 \\
\hline Copala, Sinaloa & 8 & 600 & Selva baja caducifolia & jul99, oct99, dic99 \\
\hline Rancho Mojocoan, Sinaloa & 14 & 900 & $\begin{array}{c}\text { Ecotono de selva baja caducifolia y } \\
\text { bosque de encino }\end{array}$ & ene 99 , oct 99 , dic 99 , mar00 \\
\hline Capilla del Taxte, Sinaloa & 8 & 1200 & Bosque de pino & jul99, oct 99 , dic99 \\
\hline El Batel, Sinaloa & 5 & 1600 & Bosque de pino-encino & nov98, oct99 \\
\hline El Palmito, Durango & 9 & 2000 & $\begin{array}{l}\text { Bosque de pino-encino y bosque } \\
\text { mesófilo }\end{array}$ & jun97, nov98, oct99 \\
\hline Mexiquillo, Durango & 8 & 2500 & Bosque de pino & ene99, oct99, dic99, mar00 \\
\hline Las Rusias, Durango & 6 & 2800 & Bosque de pino & oct $99, \operatorname{dic} 99$, mar00 \\
\hline
\end{tabular}

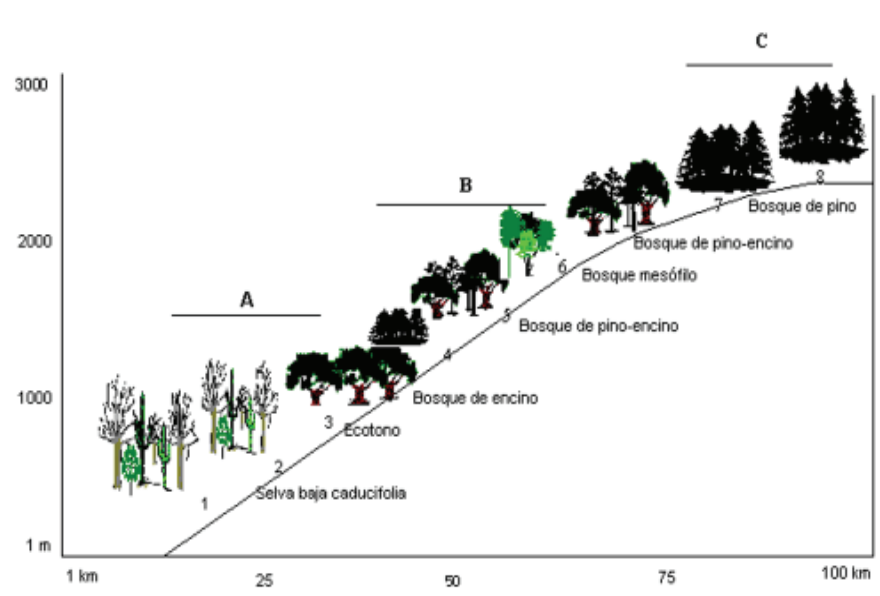

Figura 2. Perfil de vegetación en la sierra del Espinazo del Diablo de acuerdo a Vega et al. (1989). Los números representan los sitios de muestreo (altitud entre paréntesis): 1, Magistral (300 m); 2, Copala (600 m); 3, Rancho Mojocoan (900 m); 4, Capilla del Taxte (1200 m); 5, El Batel (1600 m); 6, Palmito (2000 m); 7, Mexiquillo (2500 m); y 8, Las Rusias (2800 m). Se denotan también los pisos altitudinales (A, B y C) encontrados para la avifauna.

(aproximadamente de 6:00 a 18:00 horas) y se realizaron recorridos libres por los sitios para obtener registros visuales y/o auditivos, tratando en ambos casos de cubrir la variedad de microhábitats presentes. Con ayuda de las redes y el uso ocasional de una escopeta calibre .20 se realizó una recolecta selectiva de ejemplares para conformar una colección de referencia con la mayor cantidad posible de especies, ,que se depositó en el Museo de Zoología Alfonso L. Herrera, de la Facultad de Ciencias, UNAM (MZFC). Se elaboró una lista de especies; para la asignación de presencia estacional de cada una se siguieron los criterios de Navarro y Benítez (1993), Howell y Webb (1995) y AOU (1998), con base en las fechas de presencia de las especies en el área. El estatus de conservación se asignó de acuerdo con autoridades nacionales (Ceballos y Márquez, 2000; SEMARNAT, 2002) e internacionales (BirdLife International, 2000; IUCN, 2009).

Para evaluar el esfuerzo de registro de las especies en la zona se elaboraron curvas de acumulación bajo un modelo de Clench (1979) que utiliza estimadores teóricos basados en la probabilidad de registro de nuevas especies a una lista conforme se incrementa el tiempo de muestreo (Soberón y Llorente, 1993). Para eliminar los patrones de autocorrelación, los datos se remuestrearon 100 veces siguiendo a Peterson y Slade (1998).

Para analizar los patrones de distribución general de la riqueza de especies dentro del gradiente, se utilizaron 3 métodos aplicados a una matriz de datos de presenciaausencia de cada una de las especies en los diferentes sitios de muestreo. Se utilizó el coeficiente de Jaccard (Sánchez y López, 1988) para comprender las relaciones de similitud fenética entre sitios. Para evaluar el recambio de especies a través del gradiente se utilizó el método de curvas de atenuación (Terborgh, 1971; Navarro, 1992; García-Trejo y Navarro, 2004), el cual permite observar el recambio de la avifauna que existe entre sitios y determinar si hay un cambio abrupto de especies (tasa de recambio), comparando proporciones de pérdida de especies con respecto a cada localidad. Por último, se analizaron las especies indicadoras con una prueba de 2 vías (TWINSPAN; Hill, 1979) para definir agrupamientos de sitios de muestreo y especies características de los agrupamientos generados en la clina altitudinal. Para este análisis, también se elaboró una matriz con datos binarios de presencia y ausencia y se utilizó el programa PC-ORD v. 4 (McCune y Mefford, 1999). 


\section{Resultados}

Se registró un total de 209 especies de aves durante el trabajo de campo. Al agregar los registros previos existentes en la literatura y colecciones, la lista general de la zona aumentó a 229 especies (Apéndice 1), que incluye 43 endémicas de México, las que representan el $18 \%$ del total de especies registradas en este estudio. Se obtuvo una colección de referencia de 196 ejemplares de 78 especies (de 1 a 6 ejemplares por especie). Las curvas de acumulación de especies para cada localidad (no ilustradas) indican que para cada sitio se registraron durante este trabajo los siguientes porcentajes de la riqueza total de especies esperada: Magistral 93\%, Copala 87\%, Rancho Mojocoan 93\%, Capilla del Taxte 92\%, Batel 89\%, Palmito 92\%, Mexiquillo $87 \%$ y las Rusias $89 \%$. Del estimado para
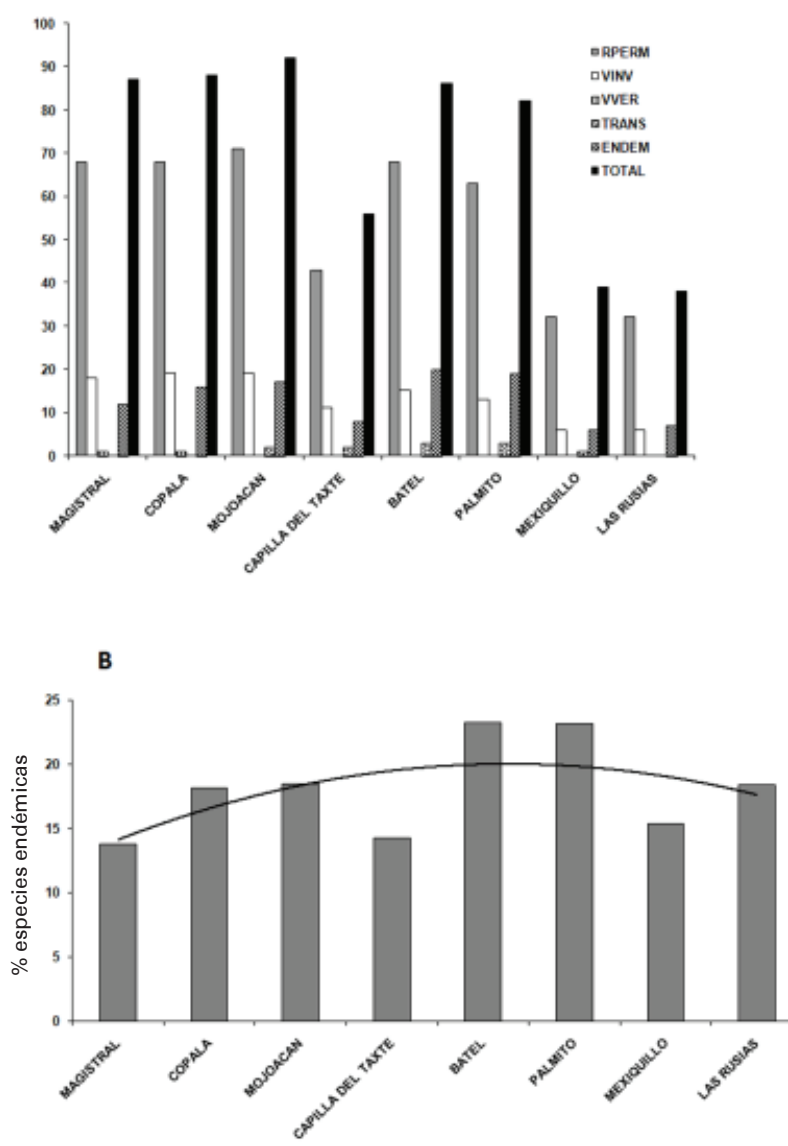

Figura 3. A, riqueza de especies por componente estacional y B, porcentaje de endemismo por cada sitio de muestreo. RPERM= residente permanente, $\mathrm{VINV}=$ visitante de invierno, $\mathrm{VVER}=$ visitante de verano, $\mathrm{END}=$ endémica y $\mathrm{TRANS}=$ transitoria. la región en su conjunto, se registraron 209 de las 237 especies esperadas, lo que representa aproximadamente el $88 \%$.

La composición estacional de la avifauna registrada en la región fue del $79 \%$ de especies residentes permanentes y el $21 \%$ de especies migratorias;,estas últimas, en su mayoría son especies visitantes de invierno. La figura 3a muestra que la riqueza de especies tiende a disminuir conforme se incrementa la altitud, patrón que es consistente en los diversos grupos estacionales de especies. La gráfica de proporción de especies endémicas por sitio (Fig. 3b) muestra que las altitudes medias contienen el mayor porcentaje de endemismo.

Los 3 métodos empleados para reconocer la existencia de asociaciones avifaunísticas a lo largo del gradiente -el fenograma de similitud faunística (Fig. 4), las

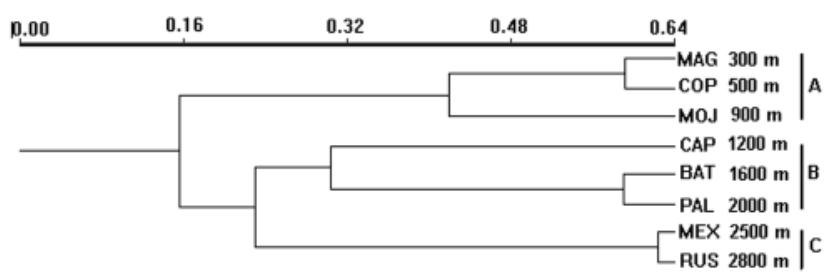

Figura 4. Fenograma de similitud de aves residentes entre los 8 sitios de muestreo. MAG, Magistral; COP, Copala; MOJ, Mojocoan; CAP, Capilla del Taxte; BAT, El Batel; PAL, El Palmito; MEX, Mexiquillo; y RUS, Las Rusias, mostrando las 3 agrupaciones principales (pisos A-C).

curvas de atenuación faunística (Fig. 5) y el análisis de TWINSPAN (Fig. 6) - coincidieron en la existencia de 3 pisos altitudinales, sugiriendo que hay una división clara de la distribución de la avifauna en el transecto. El primer grupo (piso A) está representado por las localidades bajas entre los 300 m y 900 m; se caracteriza por la avifauna de selva baja caducifolia y el ecotono de selva baja y bosque de encino, donde se registró un total de 135 especies, de las cuales 24 (18\%) fueron endémicas y 13 exclusivas de este piso. Las otras 2 agrupaciones (pisos B y C) incluyen faunas características de zonas altas. El piso B se encuentra delimitado a los sitios de muestreo de elevaciones intermedias (1 300 a $1700 \mathrm{~m}$ ) donde dominan el bosque de pino-encino y bosque mesófilo de montaña; alberga 115 especies en total, de las que 27 son endémicas (23. 4\%). El piso C está formado por las aves del bosque de pino donde se incluyen las localidades de mayor altitud del transecto (2500 m a $2800 \mathrm{~m}$ ), que alberga un total de 51 especies y 7 de ellas son endémicas, lo que representa el $11 \%$ del total.

De acuerdo con el análisis de TWINSPAN, en el piso 


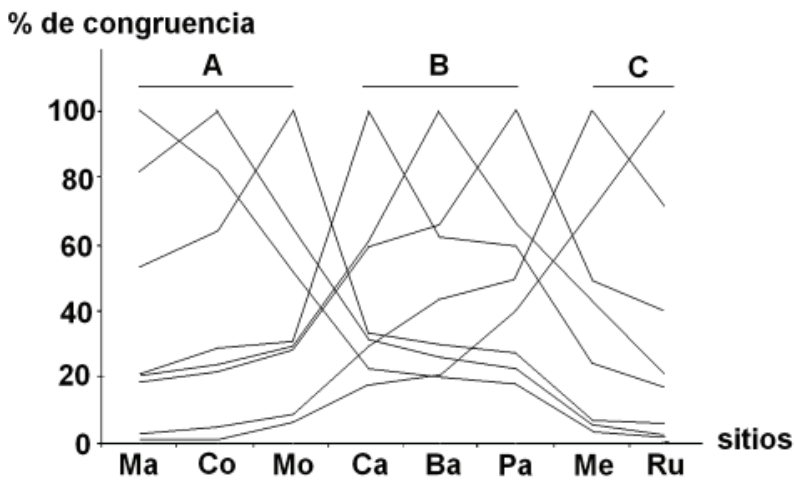

Figura 5. Curva de congruencia de especies residentes entre los sitios. MAG, Magistral; COP, Copala; MOJ, Mojocoan; CAP, Capilla del Taxte; BAT, El Batel; PAL, El Palmito; MEX, Mexiquillo; y RUS, Las Rusias. Las letras A, B y C representan cada uno de los pisos.

A se presentaron 10 especies exclusivas (Ortalis wagleri, Ciccaba virgata, Caprimulgus ridgwayi, Cynanthus latirostris, Trogon citreolus, Dryocopus lineatus, Campephilus guatemalensis, Momotus mexicanus, Saltator coerulescens y Pheucticus chrysopeplus), dos en el B (Picoides arizonae y Parula superciliosa); no hubo especies exclusivas del piso $\mathrm{C}$; sin embargo, 13 tendieron a presentarse hacia zonas altas, lo que sugiere la cercanía faunística de los pisos $\mathrm{B}$ y C, caracterizados por taxa claramente montanos como Patagioenas fasciata, Rhynchopsitta pachyrhyncha, Lampornis clemenciae, Trogon mexicanus, Colaptes auratus, Cyanocitta stelleri, Sitta carolinensis, Certhia americana, Turdus migratorius. Ridgwayia pinicola, Peucedramus taeniatus y Dendoica graciae.

De acuerdo con varios autores, 29 de las especies (14\% del total) están en alguna categoría de riesgo (Apéndice). De éstas, son relevantes las 6 que se encuentran incluidas en todas las listas prioritarias, tanto nacionales como internacionales (BirdLife International, 2000; IUCN, 2009), como Ara militaris, Rhynchopsitta pachyrhyncha, Amazona finschi, Euptilotis neoxenus, Vireo atricapilla y Cyanocorax dickeyi. Otras 42 especies están en la categoría de protección especial en la lista de NOM-Ecol059-2001 (SEMARNAT, 2002).

\section{Discusión}

La riqueza de especies de aves registrada en la zona representa un importante $21 \%$ de la avifauna nacional de acuerdo con AOU (1998). Escalante et al. (1998) mencionan que la riqueza en la mayoría de las regiones está

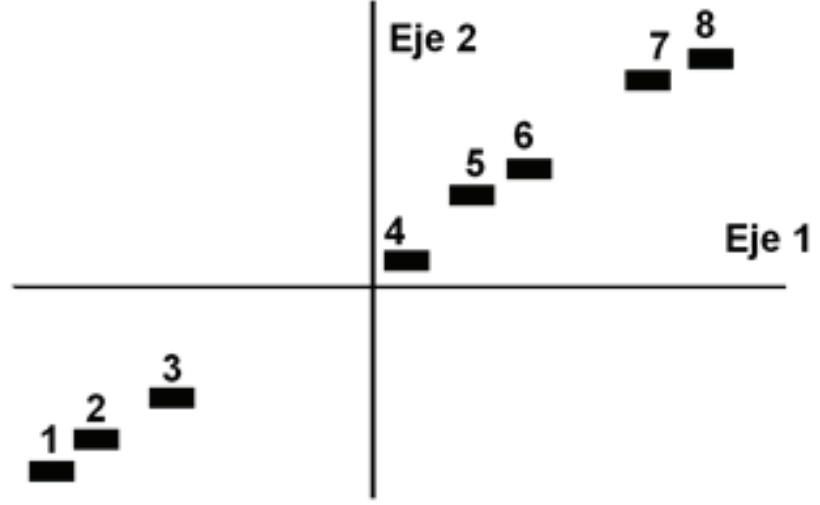

Figura 6. Agrupación de los sitios de acuerdo al análisis de TWINSPAN. 1, Magistral; 2, Copala; 3, Rancho Mojocoan; 4, Capilla del Taxte; 5, El Batel; 6, Palmito; 7, Mexiquillo; y 8, Las Rusias. El eje 1 representa la altitud y el eje 2 representa los hábitats.

relacionada con la presencia de ciertos hábitats; la selva baja caducifolia, matorral desértico, bosque de encino, bosque mesófilo de montaña, bosque de pino-encino y bosques de pino presentan una elevada riqueza de especies de aves, tanto residentes como migratorias (Hutto, 1980). Por lo tanto, en una región con gradiente altitudinal que mantiene varios de estos hábitats, como la de este estudio, la riqueza se incrementa.

Las agrupaciones avifaunísticas generadas por los 3 métodos empleados concuerdan en reconocer 3 avifaunas, asociadas en general con la distribución de los tipos de vegetación presentes en el transecto. Esto revela que la distribución de las especies está fuertemente ligada a factores como la vegetación, la altitud y la heterogeneidad ambiental. En la figura 5 se observan cambios drásticos de las pendientes de las curvas de congruencia avifaunística,entre los 900 m y los 1200 m de altitud; esta variación coincide con los cambios de vegetación, donde se muestra el efecto de los ecotonos en la discontinuidad de la distribución de las especies (Terborgh, 1985). Otro cambio menos marcado se refleja entre los $2000 \mathrm{~m}$ y $2500 \mathrm{~m}$, que probablemente se debe al aumento de altitud y disminución de la temperatura (Terborgh, 1977, 1985; Navarro, 1992). El tercer sitio de muestreo (Rancho Mojocoan, $900 \mathrm{~m}$ ) alberga la mayor riqueza de especies, posiblemente debido a la presencia de un ecotono de bosque de encino y selva baja caducifolia, presentando más elementos de esta última; es además el sitio en el cual se realizó el mayor esfuerzo de muestreo.

Los ecotonos tienen un alto grado de riqueza debido a la diversidad de hábitat, son áreas de gran productividad, además de soportar altas densidades de aves en una diversidad mayor de recursos alimenticios y posaderos que la del interior de los bosques (Villaseñor, 1993). Estos 
sitios constituyen también una barrera ecológica que limita la distribución de las especies (Terborgh, 1971; Heaney, 2001; Lomolino, 2001). Por ejemplo, para Ortalis wagleri y Trogon citreolus, los ecotonos obstaculizan el paso a altitudes superiores y para Lepidocolaptes leucogaster a zonas bajas. El bosque de encino, por su localización altitudinal y estructura, es una zona de transición entre especies de zonas bajas a zonas altas, lo que se ha demostrado para otros grupos de vertebrados como los mamíferos (Nor, 2001).

El bosque de coníferas presente en 3 sitios de muestreo (La Capilla del Taxte, localizada en el piso B; La Ciudad y Las Rusias, que representan el piso C) alberga un menor número de especies de aves respecto al resto de los tipos de vegetación, lo cual es un patrón generalizado (James y Wamer, 1982; Rahbek, 1995, 1997) que posiblemente tiene su origen en la apariencia homogénea del bosque, la ausencia casi total del sotobosque y una estacionalidad más acentuada por su localización en alturas mayores; además en bosques templados la productividad en general disminuye (Heaney 2001; Nor 2001).

Endemismo. La mayor parte de las zonas de alto endemismo en México se concentra en las montañas y desiertos (Navarro y Benítez, 1993; Stattersfield et al., 1998; Escalante et al., 1998). Esto se debe principalmente a que el aislamiento por atributos ecológicos y/o topográficos de las áreas propicia la diferenciación y especiación de las poblaciones a través del tiempo evolutivo (Terborgh, 1977; Heaney, 2001; Lomolino, 2001). En la zona de estudio, El Palmito (bosque de pino-encino y bosque mesófilo de montaña) albergó el mayor número de endémicas, lo que coincide con el patrón de una mayor proporción de endemismos en zonas montanas (Navarro, 1992; Peterson et al., 1993), como se ha probado en otras regiones del oeste del país (García-Trejo y Navarro, 2004).

Las especies endémicas de la región se agrupan en algunos patrones geográficos reconocibles. La selva baja caducifolia del noroeste de México constituye uno de los grandes centros de endemismo de Mesoamérica (Gordon y Ornelas, 2000); hay especies con distribución restringida a esta región, entre otras Ortalis wagleri, Callipepla douglasii, Forpus cyanopygius, Calocitta colliei, Cyanocorax beecheii, Corvus sinaloae y Amphispiza quinquestriata; también se registró otro grupo de endémicas que presentan una amplia distribución a lo largo del oeste de México en zonas bajas y montanas, como Amazona finschi, Amazilia violiceps, Oriturus superciliosus y Melanotis caerulescens; el tercer grupo de especies endémicas registradas en el área de estudio son las que se encuentran limitadas a las selvas caducifolias del oeste de México (Sonora a Chiapas). Finalmente, se encontraron especies restringidas a las montañas del noroeste del país, como Rhynchopsitta pachyrhyncha, Euptilotis neoxenus, Piranga erythrocephala y Cyanocorax dickeyi, y el considerado ya extinto Campephilus imperialis.

Los resultados confirman que el oeste de México es la zona geográfica con el mayor número de especies de aves endémicas en el país (Palomera-García et al., 1994; Escalante et al., 1998; Peterson y Navarro, 2000; GarcíaTrejo y Navarro, 2004), y que representa una parte muy importante de la composición biótica general de México, pues este patrón se repite en varios taxones de plantas y animales (Ramamoorthy et al., 1993; Flores-Villela y Geréz, 1994; Becerra, 2003). Por su historia geológica, se piensa que funcionó como un refugio durante el último periodo glacial (Peterson et al., 2004), resultando en importantes eventos de especiación; por ejemplo, en las endémicas que se encuentran restringidas a los bosques tropicales secos (Gordon y Ornelas, 2000). Además, el área de estudio constituye parte de una zona de transición de especies tanto neárticas como neotropicales (Halffter, 1978; Álvarez y Lachica, 1974), por lo que las aves endémicas se mezclan con la biota templada de Norteamérica que tiene una extensión al sur en su distribución en esta sierra, lo que conforma un ensamble muy particular de avifauna en esta región (Alden, 1969; Álvarez y Morrone, 2004).

Importancia para la conservación. Aunado a las peculiaridades avifaunísticas y biogeográficas ya mencionadas, la zona contiene el reducto de bosque montano húmedo con la distribución más nórdica del oeste de Mesoamérica (Hernández-Baños et al., 1995; Challenger, 1998), por lo que sus asociaciones de flora y fauna son únicas en el contexto de la biota nacional (Arriaga et al., 2000). La región contiene especies de particular relevancia para la conservación en México, como el águila real (Aquila chrysaetos) y la guacamaya verde (Ara militaris) (Ceballos y Márquez, 2000). Durante este estudio, particularmente en los hábitats montanos, se observaron de manera continua, poblaciones importantes de especies endémicas de distribución restringida y amenazadas, como la chara pinta (Cyanocorax dickeyi), la guacamaya enana (Rhynchopsitta pachyrhyncha) y el quetzal orejón (Euptilotis neoxenus), que habitan en los bosques húmedos montanos asociados a las cañadas. Se estima que la población de esta última especie ha disminuido notablemente en los últimos años, de acuerdo con información obtenida directamente de los pobladores locales (A. García L., com. pers), pues para anidar, y por lo tanto para su sobrevivencia, requiere de árboles grandes muertos en pie. Cerca de la localidad La Ciudad, Lammertink et al. (1997) encontraron nidos activos de $E$. neoxenus en árboles muertos en pie, en corredores riparios no perturbados que se localizan en cañones inaccesibles a las actividades de la industria maderera. Sin embargo, en 
esta zona operan varios aserraderos que extraen grandes cantidades de madera, ocasionando la destrucción del hábitat, y que junto con las actividades de agricultura y ganadería han modificado la vegetación natural de manera importante (Challenger, 1998). Estas actividades de tala de bosques maduros han sido la causa probable de extinción del carpintero imperial ( $C$. imperialis), que en el pasado se registró en la zona (Ceballos y Márquez, 2000). No obstante, aún se mantienen parches de vegetación poco alterados que albergan importantes poblaciones de aves y que es conveniente preservar (Vega et al., 1989).

Además de la transformación de los hábitats para la agricultura y otras actividades humanas, como la cacería (BirdLife International, 2008), el número de especies de aves en peligro de extinción se ha incrementado en los últimos años por el tráfico ilegal de algunas especies de ornato, como los loros (Cantú-Guzmán et al., 2007). En el área de estudio se practica esta actividad de manera desmedida, lo cual podría ser un factor importante en la reducción de las poblaciones de aves; se estima que las de guacamayas verdes (Ara militaris) y guacamayas enanas (R. pachyrhyncha) han sido severamente afectadas por el comercio ilegal (Arizmendi y Márquez, 2000; Rubio et al., 2007). Otras especies que se capturan con fines comerciales y de cacería, también se han calificado bajo alguna categoría de riesgo en la legislación mexicana (SEMARNAT, 2002; Apéndice 1); por ejemplo, el tinamú canelo (Crypturellus cinnamomeus); la pava cojolita (Penelope purpurascens); la codorniz Moctezuma (Cyrtonyx montezumae); los loros (Aratinga canicularis, Ara militaris, Rhynchopsitta pachyrhyncha y Amazona finschi), la chara de Beechei (Cyanocorax beecheii) y el mulato (Melanotis caerulescens). Aunque no están amenazadas, también ingresan al mercado de aves de ornato con fines comerciales, especies como los trogones (Trogon citreolus y T. elegans), los tecolotes (Glaucidium brasilianum) y algunos paseriformes (Cyanocitta stelleri, Turdus rufopalliatus, Ptilogonys cinereus, Passerina versicolor, Passerina ciris, Icterus cucullatus, I. pustulatus, Cacicus melanicterus y Carduelis psaltria). Es importante monitorear el estado de estas poblaciones sujetas a extracción en la región, para llevar a cabo acciones efectivas de manejo y conservación de la diversidad biológica.

Con base en recientes estudios, a la problemática y urgencia de conservación de la región se adiciona el hecho de que la zona alberga algunas poblaciones de aves que representan formas genética o morfológicamente diferenciadas (Dendroica coronata nigrifrons; Milá et al., 2007; Ergaticus ruber melanauris, Barrera et al., inédito), que representan linajes evolutivos independientes, por lo que varias de ellas deberían considerarse especies diferentes (Navarro-Sigüenza y Peterson, 2004). Esta peculiaridad evolutiva, producto de muchos miles de años de aislamiento de la sierra Madre Occidental, agrega gran valor de conservación a las aves del área.

A pesar de lo anterior y a que la región está considerada una prioridad de conservación tanto por su avifauna (AICA de Importancia Global [G1] "Río Presidio-Pueblo Nuevo"; Arizmendi y Márquez, 2000) como por su valor biológico nacional (Región Terrestre Prioritaria "Río Presidio"; Arriaga et al., 2000) e internacional (zona de alta concentración de vertebrados en riesgo; Rodrigues et al., 2006), aún no se han tomado decisiones oficiales para su preservación.

Recientemente, se decretaron 2 zonas de protección biológica cercanas al área de estudio en Durango: El Tecuán (847 ha) y la Barranca de Santa Bárbara (65 ha) (Cárdenas, 2008); sin embargo, son áreas de recreación y explotación cinegética, por lo que la adecuada conservación de los bosques montanos y los endemismos del Espinazo del Diablo son aún un reto para la conservación de la biodiversidad del occidente de México.

\section{Agradecimientos}

Este estudio se benefició en diversas etapas de los comentarios de J. F. Villaseñor, A. T. Peterson, L. A. Sánchez-González, K. Babb, L. Márquez, G. Ibáñez, E. Figueroa, P. Feria, A. Gordillo, B. Hernández Baños, P. Ramírez-Bastida y 2 revisores anónimos. En el trabajo logístico y de campo se obtuvo apoyo incondicional de A. García Loya, E. Rodríguez-Ayala ${ }^{\dagger}$, E. Álvarez, P. Uriarte, F. Rebón, S. López de Aquino, E. García-Trejo, H. Cervantes, B. Granados, M. Honey y E. López, así como de la Universidad Autónoma de Sinaloa (Culiacán). A los curadores de las colecciones científicas de las siguientes instituciones: American Museum of Natural History, Academy of Natural Sciences of Philadelphia, Bell Museum (University of Minnesota), Natural History Museum (British Museum), Carnegie Museum of Natural History, California Academy of Sciences, Canadian Museum of Nature, Denver Museum of Natural History, Delaware Museum of Natural History, Florida Museum of Natural History, Field Museum, University of Kansas, Los Angeles County Museum, Louisiana State University Museum of Zoology, Museum of Comparative Zoology (Harvard University), Moore Laboratory of Zoology, University of Michigan Museum of Zoology, Museum of Vertebrate Zoology (UC Berkeley), Museo de Zoología (Facultad de Ciencias UNAM), Royal Ontario Museum, San Diego Natural History Museum, Southwestern College, University of Arizona, University of California Los Angeles, Western Foundation of Vertebrate Zoology, 
United States National Museum y Peabody Museum (Yale University), por brindarnos el acceso a sus datos. En las diversas etapas se obtuvo apoyo financiero de CONACYT (R 27961), PAPIIT (IN 214200 y 216408) así como una beca de estudios de posgrado otorgada a M. N. MedinaMacías.

\section{Literatura citada}

Alden, P. 1969. Finding the birds in western Mexico: a guide to the states of Sonora, Sinaloa, and Nayarit. University of Arizona Press, Tucson. 138 p.

Álvarez, T. y F. de Lachica. 1974. Zoogeografía de los vertebrados de México. In El escenario geográfico . II. Recursos naturales, A. Flores, L. González, T. Álvarez y F. de Lachica, (eds.). SEP-INAH, México. p. 219-257.

Álvarez, E. y J. J. Morrone. 2004. Propuesta de áreas para la conservación de aves de México, empleando herramientas panbiogeográficas e índices de complementariedad. Interciencia 29:112-120.

AOU (American Ornithologists' Union). 1998. Check-list of North American Birds, séptima edición, Washington, D.C. 829 p.

Arizmendi, M. C., y L. Márquez V. (eds.) 2000. Áreas de importancia para la conservación de las aves de México. CIPAMEX, México, D.F. 440 p.

Arriaga, L., J. M. Espinoza, C. Aguilar, E. Martínez, L. Gómez y E. Loa (coords.) 2000. Regiones terrestres prioritarias de México. Escala de trabajo 1:1 000 000. Comisión Nacional para el Conocimiento y Uso de la Biodiversidad, México, D. F. 609 p.

Becerra, J. X. 2003. Evolution of Mexican Bursera (Burseraceae) inferred from ITS, ETS, and 5S nuclear ribosomal DNA sequences. Molecular Phylogentics and Evolution 26:300-309.

BirdLife International. 2000. Threatened birds of the world. Lynx, Barcelona /BirdLife International, Cambridge. 852 p.

BirdLife International. 2008. Critically endangered birds: a global audit. BirdLife International, Cambridge. $18 \mathrm{p}$.

Cantú-Guzmán, J. C., M. E. Sánchez-Saldaña, M. Grosselet y J. Silva-Gámez. 2007. Tráfico ilegal de pericos en México: una evaluación detallada. Defenders of Wildlife, Washington, D.C. $74 \mathrm{p}$.

Cárdenas, J. C. 2008. Durango tiene dos nuevas áreas naturales protegidas. El Siglo de Torreón, 30 julio 2008. (http://www. elsiglodetorreon.com.mx/noticia/368208); última consulta: 05.VIII.2002.

Ceballos, G. y L. Márquez. 2000. Las aves de México en peligro de extinción. Instituto de Ecología, UNAM / Comisión Nacional para el Conocimiento y Uso de la Biodiversidad / Fondo de Cultura Económica, México, D.F. 430 p.

Challenger, A. 1998. Utilización y conservación de los ecosistemas terrestres de México: pasado, presente y futuro. Comisión Nacional para el Uso y Conocimiento de la Biodiversidad / Instituto de Biología, UNAM y Agrupación Sierra Madre, S.C., México, D.F. 847 p.

Clench, H. 1979. How to make regional lists of butterflies: some thoughts. Journal of the Lepidopterists' Society 33:216-231.

Crossin, R. S. 1967. The breeding biology of the Tufted Jay.
Occasional Papers Western Foundation of Vertebrate Zoology 1:265-300.

Escalante, P., A. G. Navarro S. y A. T. Peterson. 1998. Un análisis geográfico, ecológico e histórico de la diversidad de las aves terrestres de México. In Diversidad biológica de México. orígenes y distribución. T. P. Ramammoorthy, R. Bye, A. Lot y J. Fa (eds.). Instituto de Biología, UNAM, México. D.F. p. 279-304.

Flores-Villela, O. A. y P. Gerez. 1994. Biodiversidad y conservación en México: vertebrados, vegetación y uso del suelo, segunda edición, Universidad Nacional Autónoma de México / Comisión Nacional para el Conocimiento y Uso de la Biodiversidad. 439 p.

García, E. 2004. Modificación al sistema de clasificación climática de Köppen. Instituto de Geografía, UNAM, México, D. F. 91 p.

García-Trejo, E. A. y A. G. Navarro. 2004. Patrones biogeográficos de la riqueza de especies y el endemismo de la avifauna en el oeste de México. Acta Zoológica Mexicana (n. s.) 20:167185.

Gordon, C. E. y J. F. Ornelas 2000. Comparing endemism and habitat restriction in Mesoamerican tropical deciduous forest birds: implications for biodiversity conservation planning. Bird Conservation International 10:289-303.

Halffter, G. 1978. Un nuevo patrón de dispersión en la zona de transición mexicana: El mesoamericano de montaña. Folia Entomológica Mexicana 39-40:219-222.

Heaney, L. R. 2001. Small mammal diversity along elevational gradients in the Philippines: an assesment of patterns and hypotheses. Global Ecology and Biogeography 10:15-39.

Hernández-Baños, B. E., A. T. Peterson, A. G. Navarro-Sigüenza y P. Escalante-Pliego. 1995. Bird faunas of the humid montane forests of Mesoamerica: biogeographic patterns and priorities for conservation. Bird Conservation International 5:251-277.

Hill, M. O. 1979. TWINSPAN: a FORTRAN program for arranging multivariate data in an ordered two way table by classification of the individuals and attributes. Section of Ecology and Systematics, Cornell University, Ithaca, New York. 90 p.

Howell, S. N. G. y S. Webb. 1995. A guide to the birds of Mexico and northern Central America. Oxford University Press, London. $851 \mathrm{p}$.

Hutto, R. L. 1980. Winter habitat distribution of migratory land birds in western México, with special reference to small foliagegleaning insectivores: In Migrant birds in the neotropics: ecology, behavior and conservation, A. Keast y E. Morton (eds.). Smithsonian Institution Press, Washington, D. C. 181-203.

IUCN (International Union for Conservation of Nature). 2009. IUCN Red List of threatened species. Version 2009.1. <www. iucnredlist.org>. Versión consultada: 16.VI.2009.

James, F. C. y O. N. Wamer 1982. Relationships between temperate forest bird communities and vegetation structure. Ecology 63:159-171.

Körner, C. 2000. Why are there global gradients in species richness? Mountains might hold the answer. Trends in Ecology and Evolution 15:513-514.

Körner, C. y E. M. Spehn (eds.). 2002. Mountain Biodiversity: a global assessment. Parthenon, CRC, Basel. 336 p.

Lammertink, J. M., J. A. Rojas Tomé, F. M. Casillas Orona y R. L. 
Otto 1997. Situación y conservación de los bosques antiguos de pino-encino de la sierra Madre Ocidental y sus aves endémicas. CIPAMEX, México, D.F. 103 p.

Lomolino, M. 2001. Elevation gradients of species density: historical and prospective views. Global Ecology and Biogeography 10:313.

McCune, B. y M. J. Mefford. 1999. PC-ORD 4.26 for Windows. Multivariate analysis of ecological data, MjM Software Design, Gleneden Beach, Oregon. 24 p.

Milá, B., T. B. Smith y R. K. Wayne. 2007. Speciation and rapid phenotypic differentiation in the yellow-rumped warbler (Dendroica coronata) complex. Molecular Ecology 16:159173.

Monterrubio-Rico, T., E. Enkerlin-Hoeflich y R. B. Hamilton. 2002. Productivity and nesting success of Thick-billed Parrots. Condor 104:788-794.

Moore, R.T. 1938. Unusual birds and extensions of ranges in Sonora, Sinaloa and Chihuahua, Mexico. Condor 40:23-28.

Navarro, A. G. 1992. Altitudinal distribution of birds in the sierra Madre del Sur, Guerrero, Mexico. Condor 94:29-39.

Navarro, A. G. y H. Benítez. 1993. Patrones de riqueza y endemismo de las aves. In Biología y problemática de los vertebrados en México. O. Flores y A. Navarro (eds.). Revista Ciencias (Número especial) 7:45-54.

Navarro, A. G., A. T. Peterson y A. Gordillo-Martínez. 2003. Museums working together: the atlas of the birds of Mexico. In Why museums matter: avian archives in an age of extinction, N. C. Collar, C. Fisher y C. Feare (eds.). Bulletin British Ornithologists' Club Supplement 123A. p. 207-225

Navarro-Sigüenza, A. G. y A. T. Peterson. 2004. An alternative species taxonomy of the birds of Mexico. Biota Neotropica 4. http://www.biotaneotropica.org.br/v4n2/pt/abstract?taxonomicreview+BN03504022004; última consulta: 05.VIII.2009.

Nor, S. M. 2001. Elevational diversity patterns of small mammals on Mount Kinabalu, Sabah, Malaysia. Global Ecology and Biogeography 10:41-62.

Palomera-García, C., E. Santana y R. Amparán-Salido. 1994. Patrones de distribución de la avifauna en tres estados del occidente de México. Anales del Instituto de Biología Universidad Nacional Autónoma de México, Serie Zoología 5:137-175.

Peterson, A. T., O. Flores-Villela, L. León, J. Llorente, A. Luis, A. G. Navarro, M. Torres e I. Vargas. 1993. Conservation priorities in Mexico: moving up in the world. Biodiversity Letters 1:33-38.

Peterson, A. T. y N. A. Slade. 1998. Extrapolating inventory results into biodiversity estimates and the importance of stopping rules. Diversity and Distributions 4:95-105.

Peterson, A. T. y A. G. Navarro S. 2000. Western Mexico: a significant centre of avian endemism and challenge for conservation action. Cotinga 14:42-46.

Peterson, A. T., E. Martínez-Meyer y C. González-Salazar. 2004. Reconstructing the Pleistocene geography of the Aphelocoma jays (Corvidae). Diversity and Distributions 10:237-246.

Rahbek, C. 1995. The elevational gradient of species richness: a uniform pattern? Ecography 18:200-205.

Rahbek, C. 1997. The relationship among area, elevational, and regional species richness in Neotropical birds. American Naturalist 149:875-902.
Ramamoorthy, T. P., R. Bye, J. Fa y A. Lot (eds.). 1993. Biological diversity of Mexico: origins and distributions. Oxford University Press, New York. 812 p.

Rickart, E. 2001. Elevational diversity gradients, biogeography, and the structure of montane mammal communities in the intermountain region of North America. Global Ecology and Biogeography 10:77-100.

Rodrigues, A. S. L., J. D. Pilgrim, J. F. Lamoreux, M. Hoffmann y T. M. Brooks. 2006. The value of IUCN Red List for conservation. Trends in Ecology and Evolution 21:71-76.

Rodríguez-Yáñez, C., R. Villalón C. y A. G. Navarro S. 1994. Bibliografía de las aves de México (1825-1992). Publicaciones Especiales del Museo de Zoología de la Facultad de Ciencias UNAM 8:1-153.

Rubio, Y., A. Beltrán, F. Aviléz, B. Salomón y M. Ibarra. 2007. Conservación de la guacamaya verde (Ara militaris) y otros psitácidos en una reserva ecológica universitaria, Cosalá, Sinaloa, México. Mesoamericana 11:58-64.

Rzedowski, J. 1978. Vegetación de México. Limusa, México, D.F. $381 \mathrm{p}$.

Sánchez, O. y López, G. 1988. Theoretical analysis of some indices of similarity as applied to biogeography. Folia Entomologica Mexicana 75:119-145.

Sánchez-Cordero, V. 2001. Elevational gradients of diversity for rodents and bats in Oaxaca, Mexico. Global Ecology and Biogeography 10:63-76.

SEMARNAT (Secretaría del Medio Ambiente y Recursos Naturales). 2002. Norma Oficial Mexicana NOM-059-ECOL2001, Protección ambiental-Especies nativas de México de flora y fauna silvestres-Categorías de riesgo y especificaciones para su inclusión, exclusión o cambio-Lista de especies en riesgo. Diario Oficial de la Federación, 6 marzo 2002.

Soberón, J. y J. Llorente. 1993. The use of species accumulation functions for the prediction of species richness. Conservation Biology 7:480-488.

Stattersfield, J. A., M. J. Crosby, A. J. Long y D. C. Wege. 1998. Endemic birds areas of the world, priorities for biodiversity conservation, BirdLife International Series 7, Cambridge. 846 p.

Terborgh, J. 1971. Distribution on enviromental gradients: theory and a preliminary interpretation of distributional patterns in the avifauna of the Cordillera Vilcabamba, Perú. Ecology 52:2340.

Terborgh, J. 1977. Bird species diversity on an Andean elevational gradient. Ecology 58:1007-1019.

Terborgh, J. 1985. The role of ecotones in the distribution of Andean birds. Ecology 6:1237-246.

Terborgh, J. y J. S.Weske. 1975. The role of competition in the distribution of the Andean birds. Ecology 56:562-576.

Vega, A., R., G. A. Bojórquez y F. Hernández 1989. Flora de Sinaloa. Secretaría de Educación Pública-Universidad Autónoma de Sinaloa, Culiacán. 49 p.

Villaseñor, G., J. F. 1993. The importance of agricultural border strips in the conservation of North American migratory landbirds in Western Mexico. M. A. Thesis, University of Montana. 131 p.

Whitney, B. 1986. Finding the Tufted Jay (Cyanocorax dickeyi) in Sinaloa, Mexico. MBA Bulletin Board 1:2-3. 


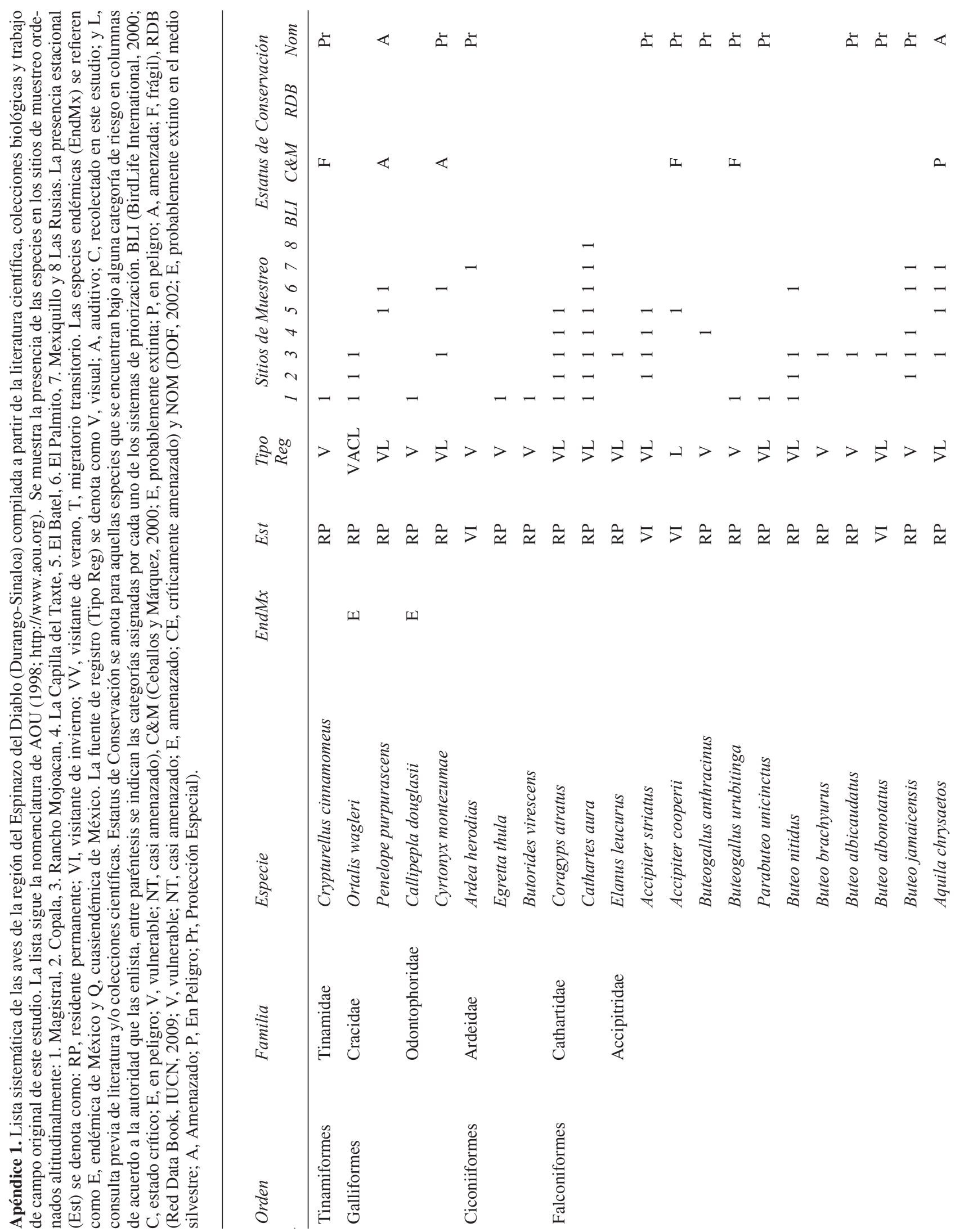




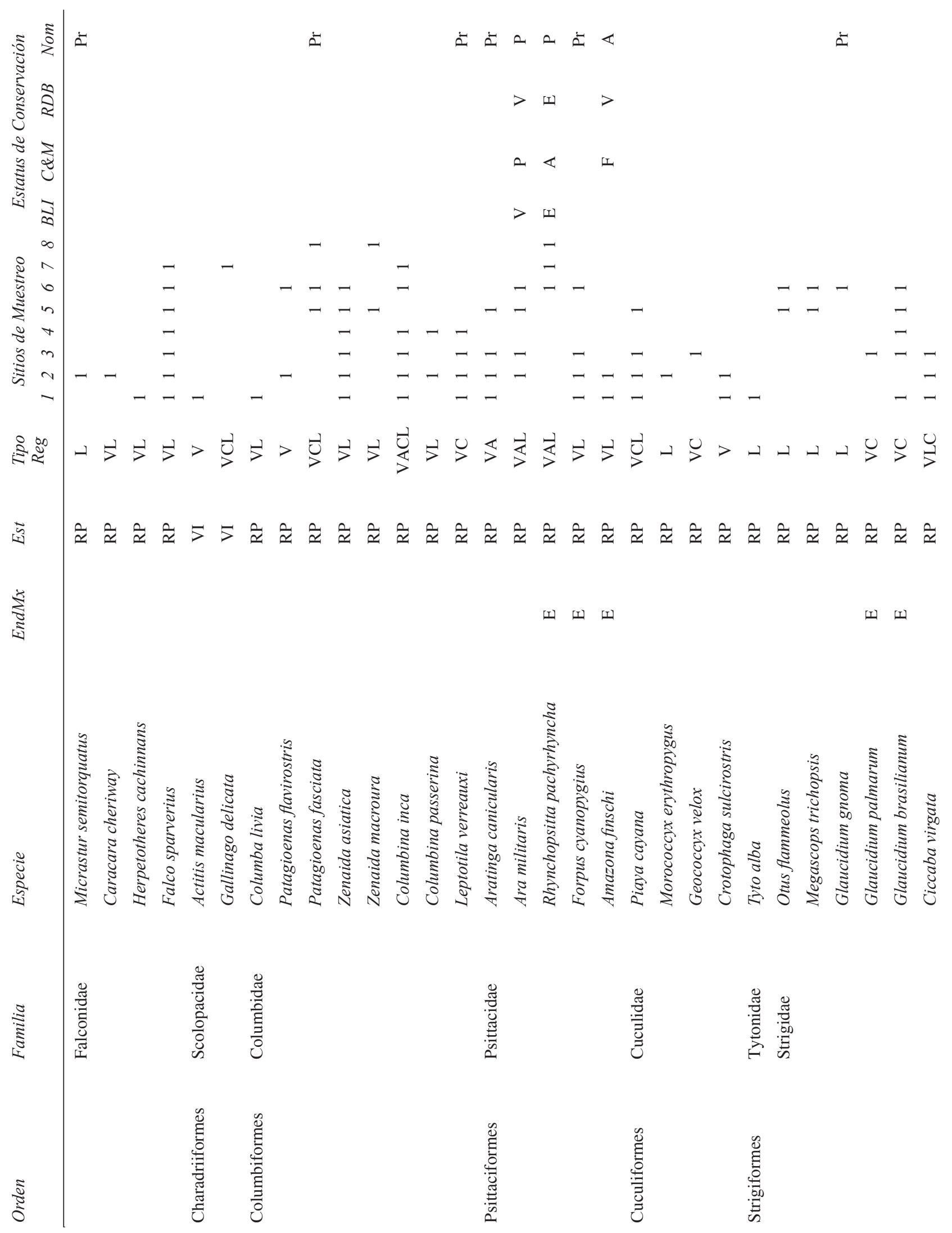




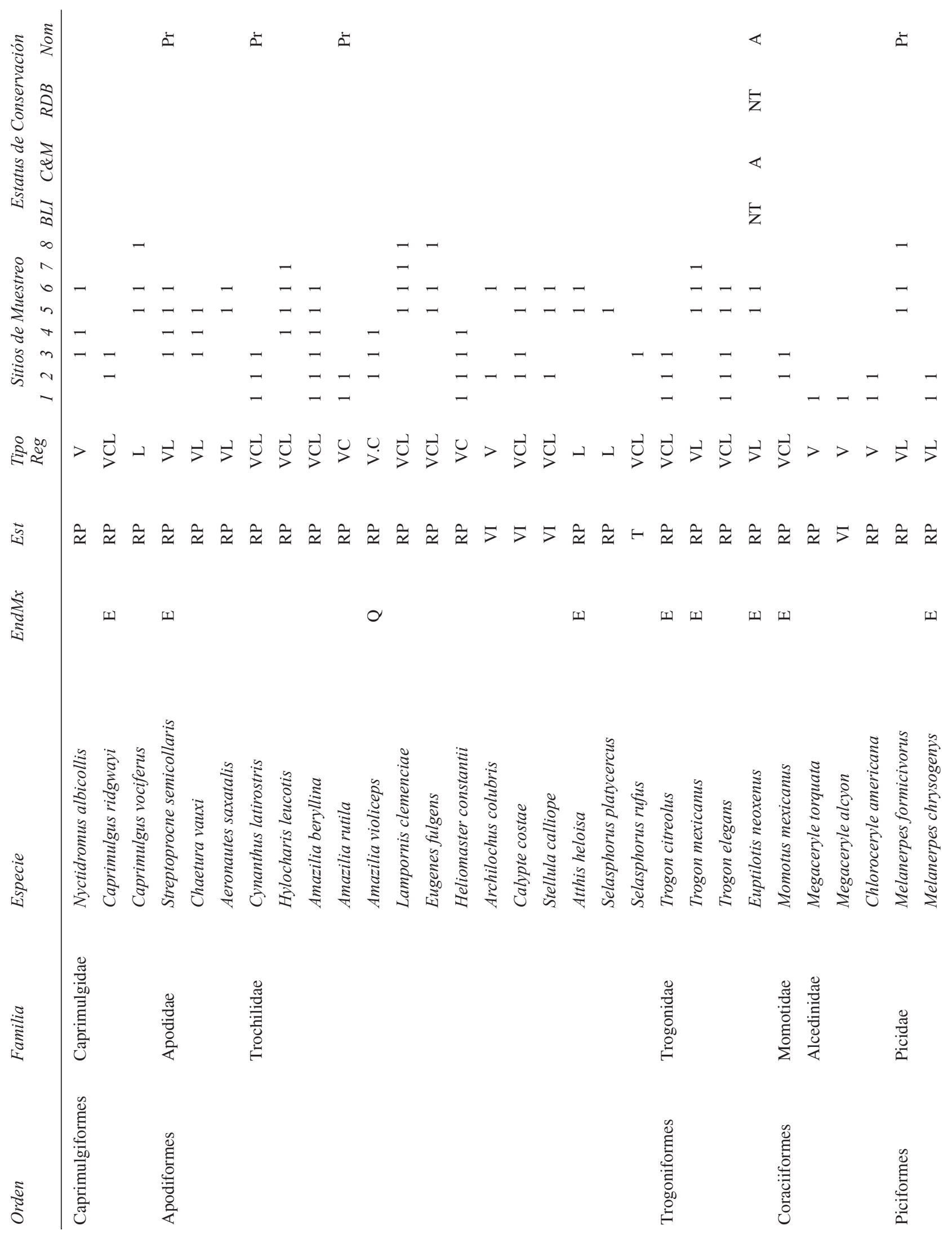




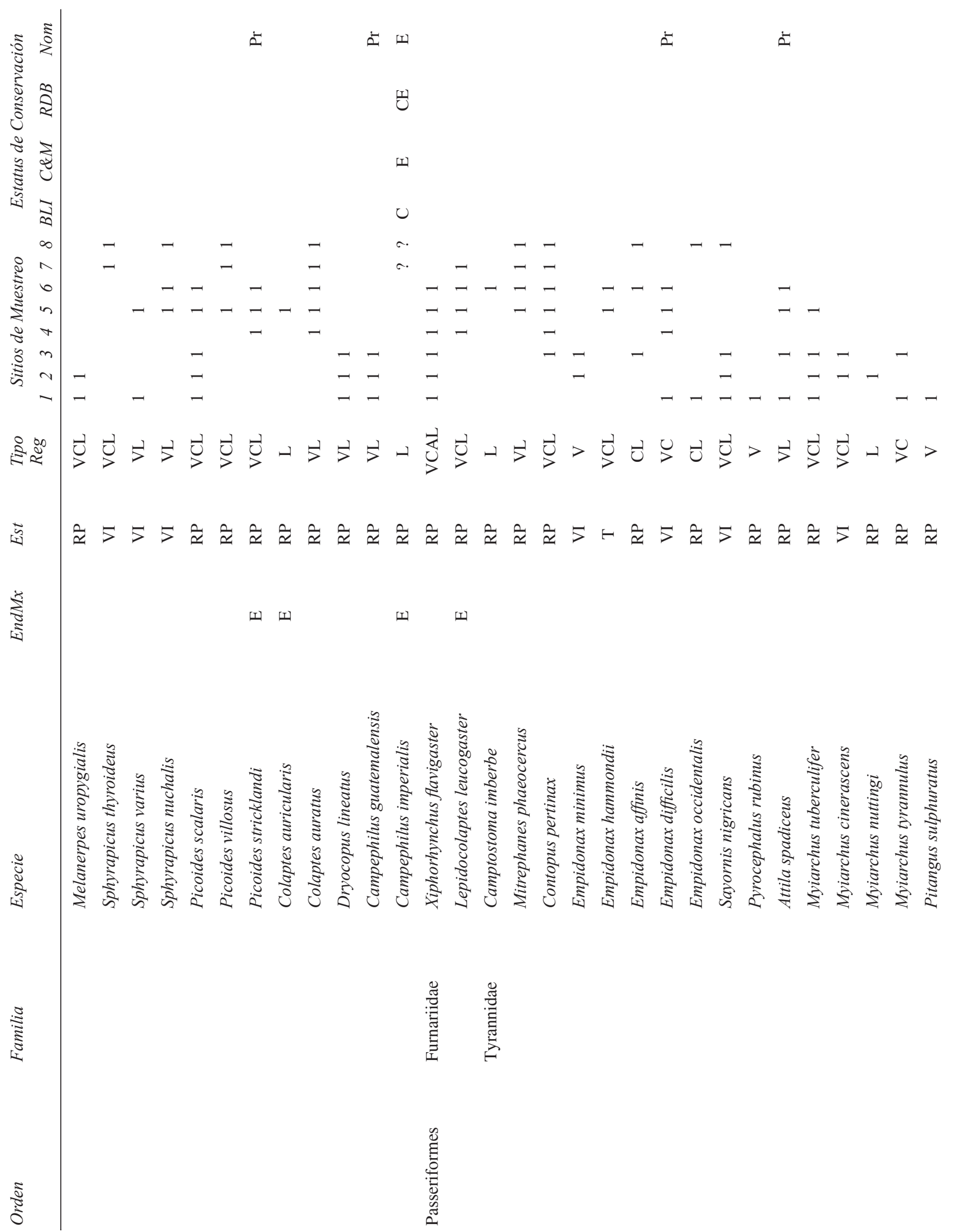




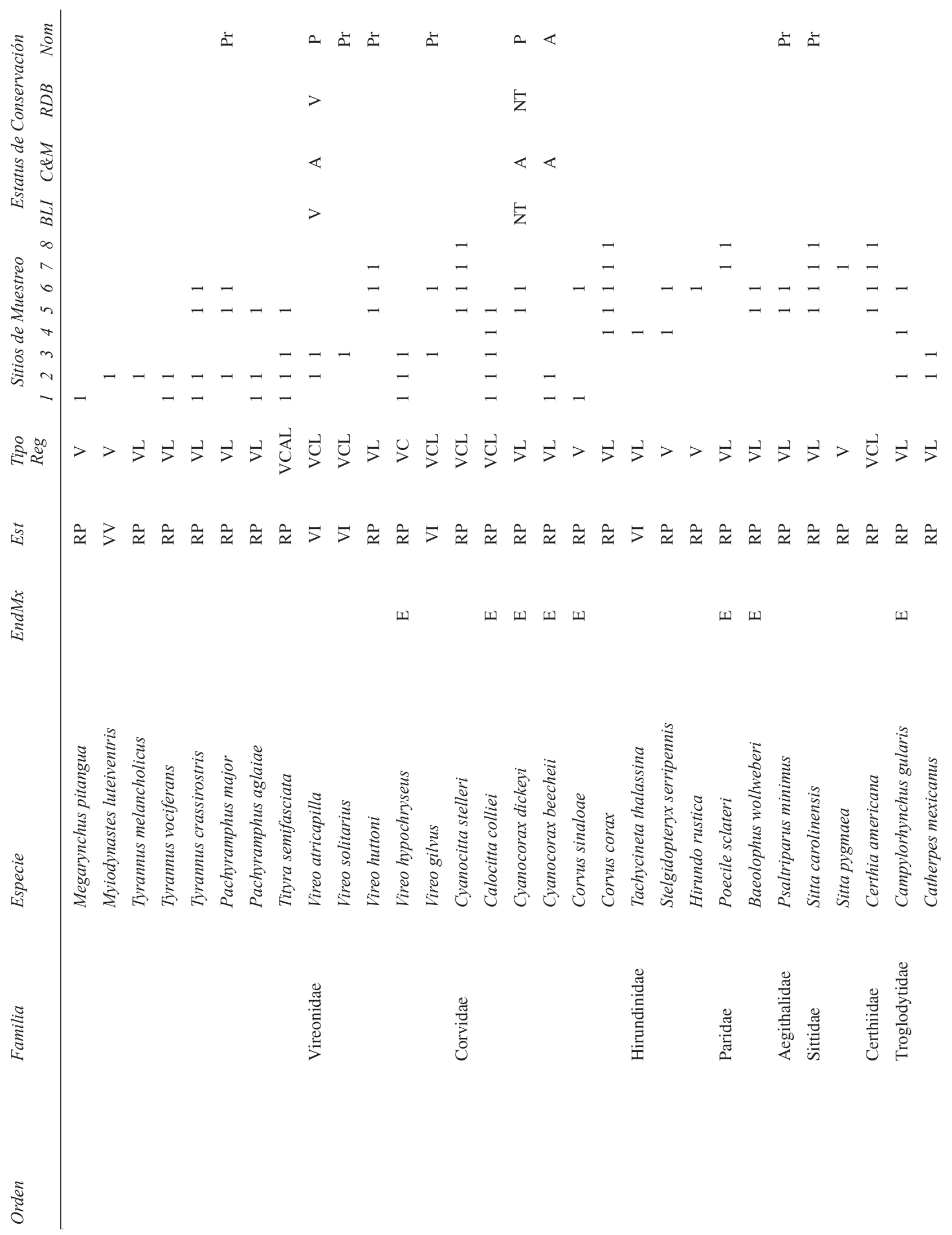




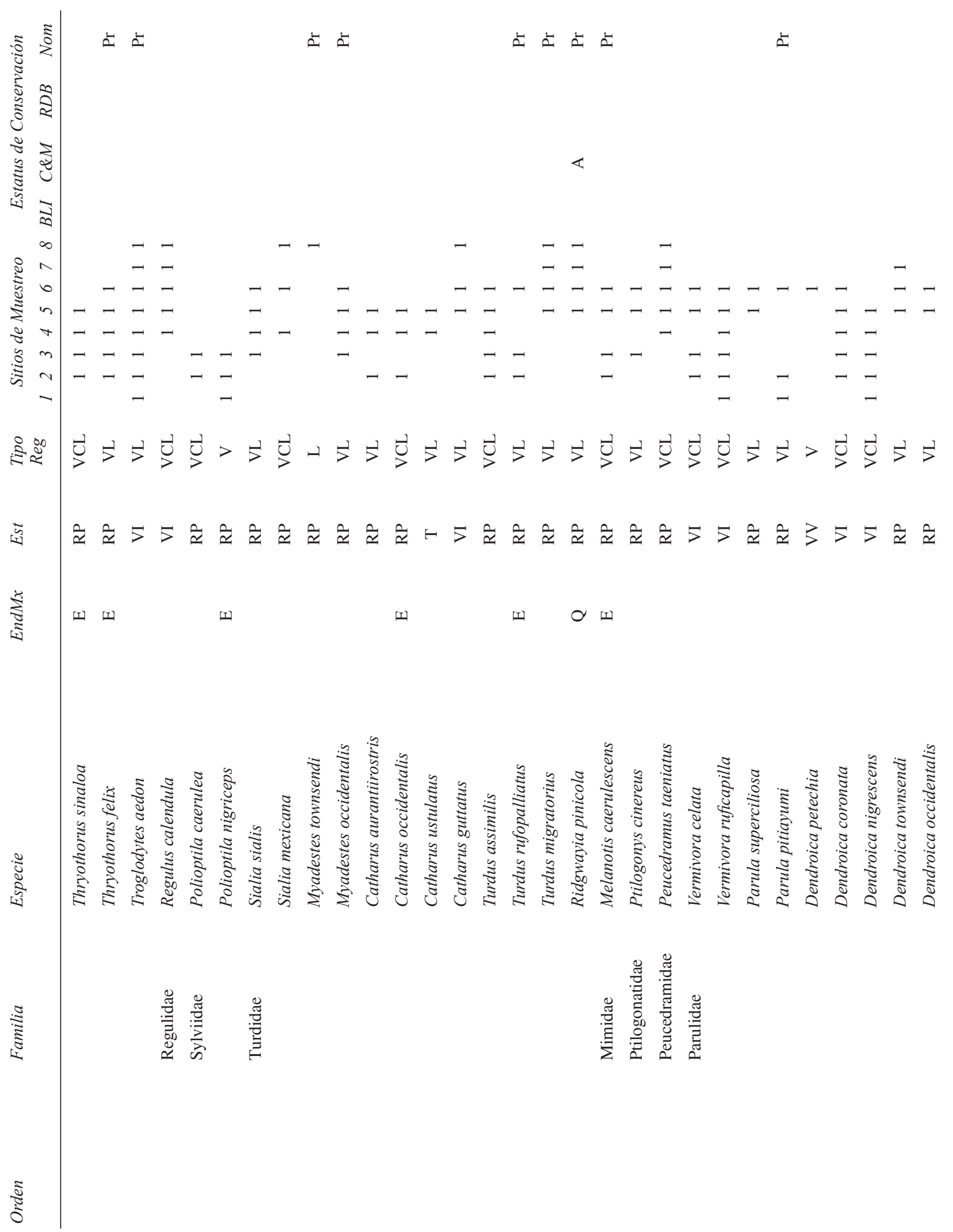




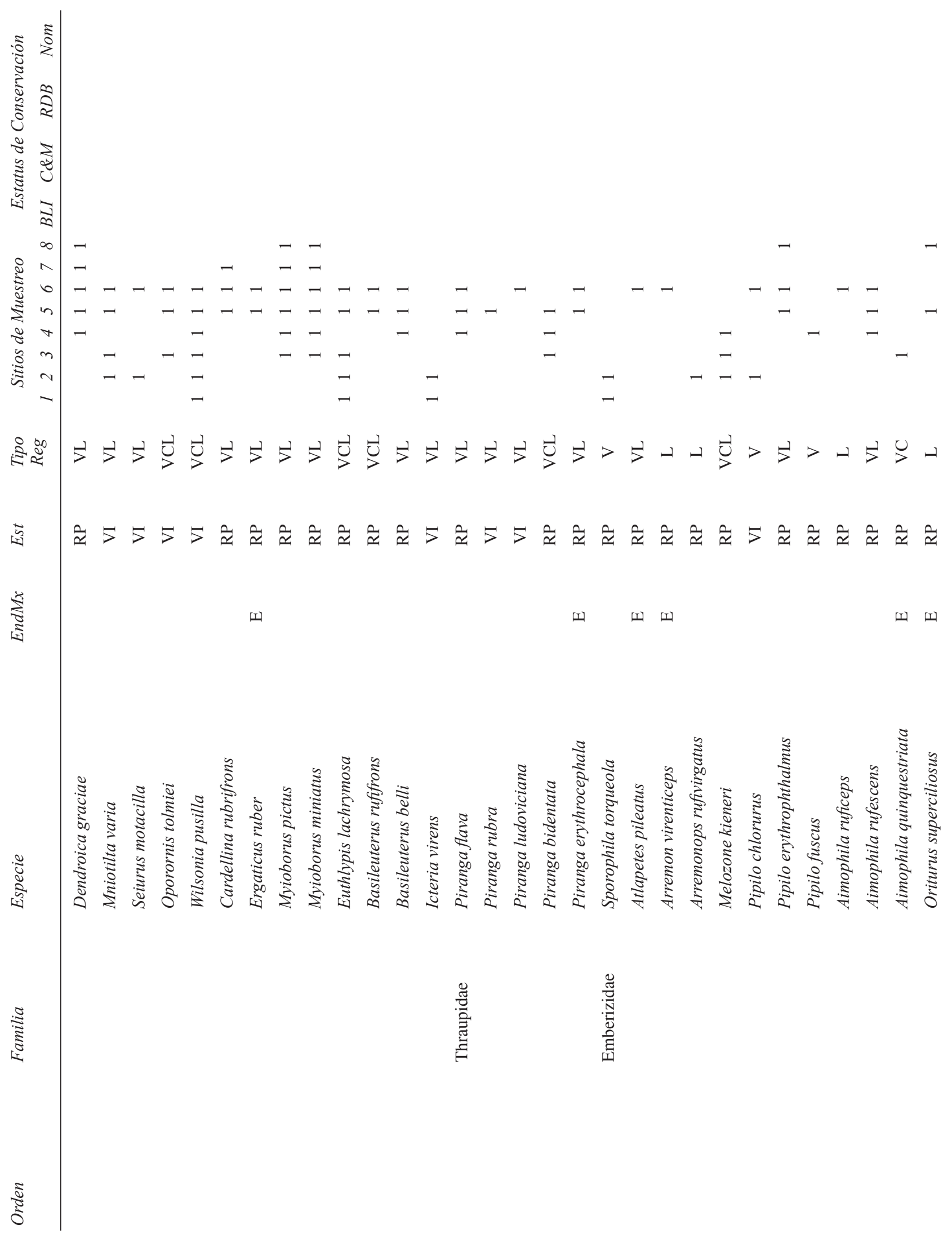




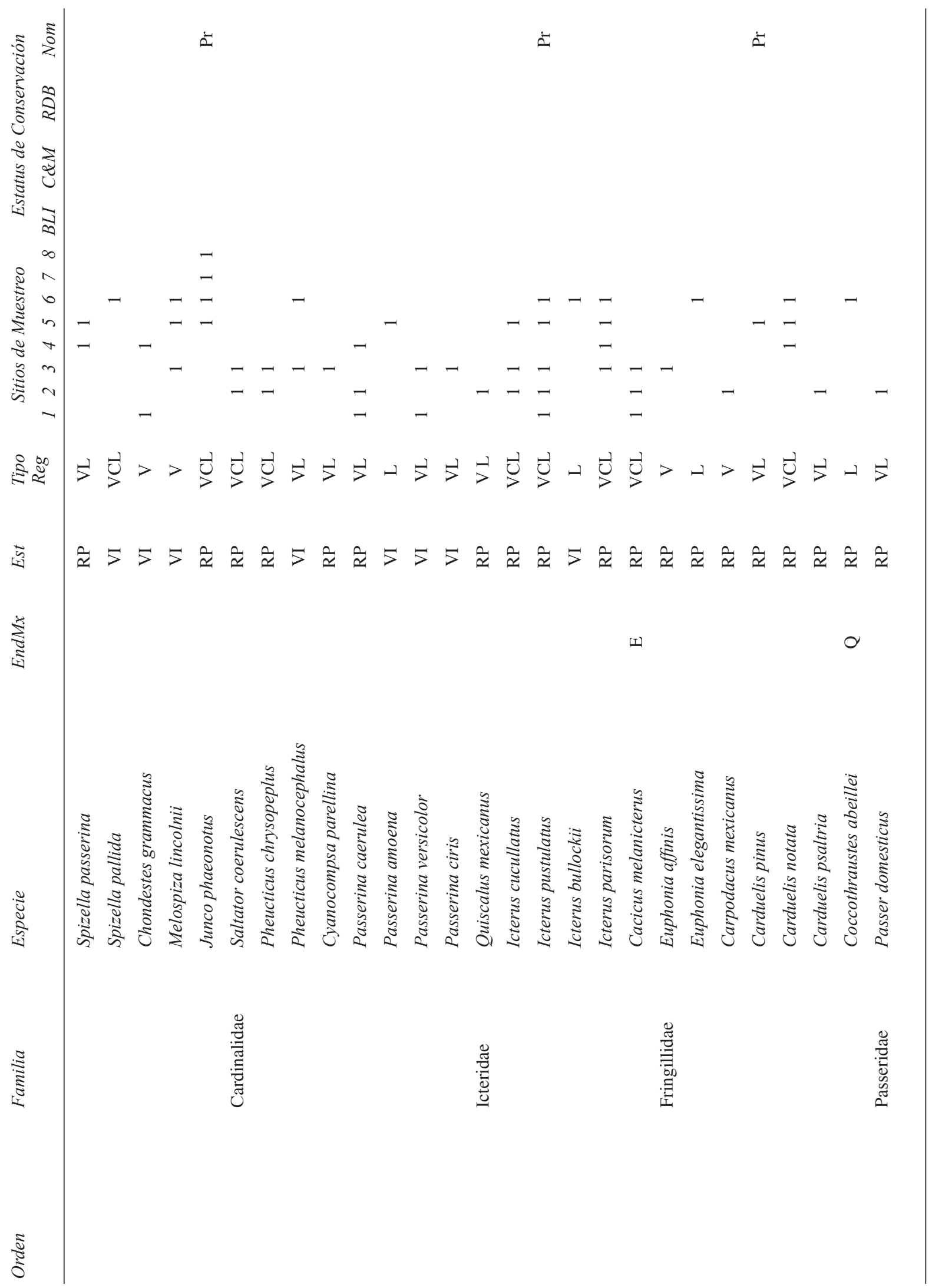

